\title{
Biotechnological method for decreasing hazardous compound (acrylamide) formation during phyto food product processing.
}

\author{
Alemzadeh I*, M. Matouri \\ Department of Chemical and Petroleum Engineering, Sharif University of Technology, Tehran, Iran
}

Accepted on November 30, 2017

Acrylamide is a toxicant and defined as a suspected human carcinogen by the International Agency for Research on Cancer $[1,2]$. In 2002, a research group showed that acrylamide is found in a range of cooked foods, with the highest content range in carbohydrate-rich foods, 50-4000 $\mu \mathrm{g} \mathrm{Kg}^{-1}$, and a range of 5-50 $\mu \mathrm{g} \mathrm{Kg}^{-1}$ in protein-rich foods [2]. The outcome of this review was that the main acrylamide containing food groups were identified as cereal-based products and potatobased products [3]. Acrylamide in foods is formed in Maillard reaction pathway, which is a synthesis of asparagine, as an amino group, and a reducing sugar such as glucose and fructose (Figure 1) [4,5]. This reaction affects the development of flavor and color [6]. This chemical reaction mainly occurs at high temperatures $\left(>120^{\circ} \mathrm{C}\right)$ and low moisture conditions [7]. Meanwhile, the relationship between these reactants and final product (acrylamide) is surprisingly complicated. Addition of the enzyme asparaginase, obtained from microbial sources has been reported as a method to reduce the formation of acrylamide since it results in the hydrolysis of asparagine to aspartic acid and ammonia (Figure 2). Added asparaginase in bread making showed a reducing effect on acrylamide formation $(\mathrm{P} \leq 0.0001)$. Baking temperature significantly increased the acrylamide content in bread $(\mathrm{P} \leq 0.0001)$. A strong correlation was found between the baking temperature and acrylamide formation. Baking time and its interaction with asparaginase had a low but significant reducing effect on acrylamide content in bread $(\mathrm{P} \leq$ 0.0001). Three parameters: cooking temperature, cooking time and enzyme concentration( $\mathrm{U} \mathrm{Kg}^{-1}$ ) have been optimized using response surface methodology, their values obtained $245.71^{\circ} \mathrm{C}$, $14.55 \mathrm{~min}$ and $752.15 \mathrm{U} \mathrm{Kg}^{-1}$, respectively $[7,8]$.

Potato has high levels of acrylamide precursors; hence, at the presence of high temperatures acrylamide is generated. This toxic substance can have concentrations of even more than $4000 \mu \mathrm{g} / \mathrm{kg}$ in potato products [8]. Further supports the finding that addition of the enzyme asparaginase is a method to reduce the formation of acrylamide since it results in the hydrolysis of the critical precursor (asparagine) for acrylamide formation in bread and potato products.

The main aim is to compare the reduction of acrylamide in potato crisps using two kinds of asparaginase enzyme; the first enzyme is commercial but the second is an enzyme made from Candida utilize specifically for food treatment. Before frying, samples were treated in one of following ways: Washing in distilled water (control I); Blanching in hot water; Immersion in commercial asparaginase (asparaginase of Candida utilis) solution; Both blanching in hot water and immersion in commercial asparaginase (asparaginase of Candida utilis) solution; Blanching in hot water plus immersion in medium temperature water (control II). While commercial asparaginase reduces acrylamide formation by $39 \%$, asparaginase obtained from Candida utilize makes a higher reduction of $58 \%$ in potato crisps. However, both enzymes in combination with blanching inhibit much higher amount of acrylamide formation. The

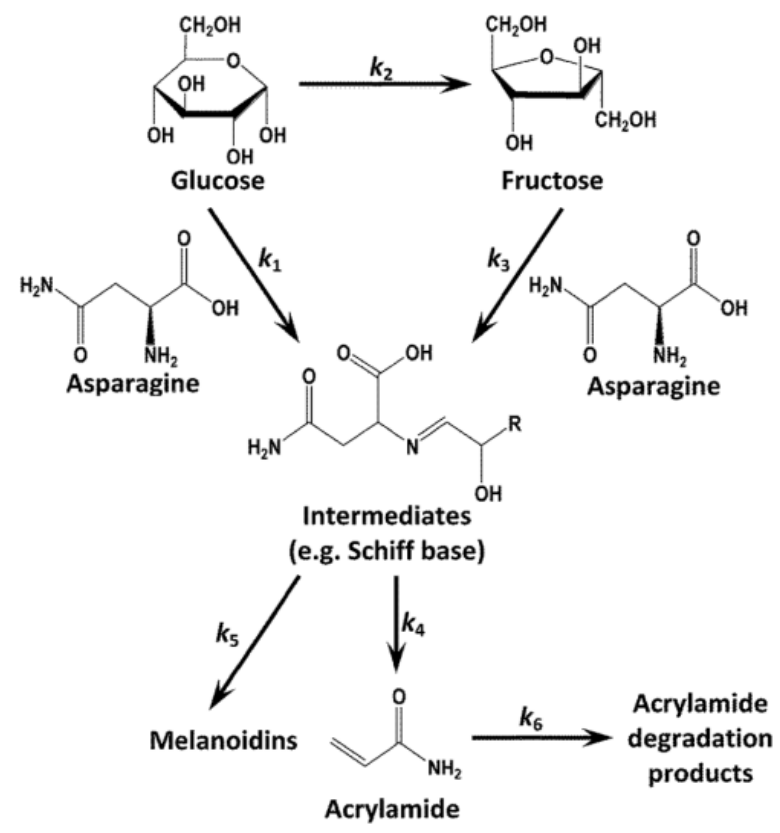

Figure 1: Acrylamide formation during sugar and protein based foods. 

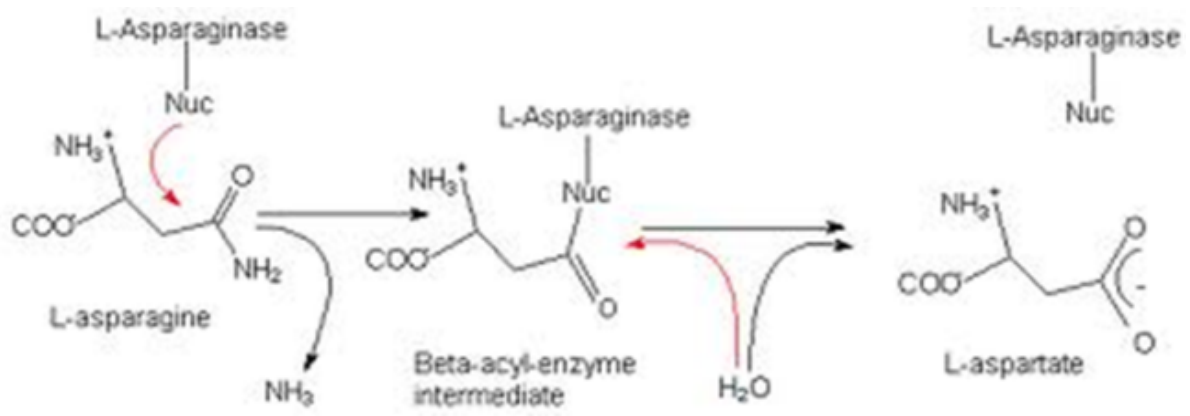

Figure 2: L-asparaginase reaction on L-asparagine.

maximum reduction of acrylamide is $95 \%$ caused by commercial treatment plus blanching. For conclusion, enzymatic process could be suggested as a safe and convenient method for preventing acrylamide formation in bread making and potato products processing.

\section{References}

1. Bologna LS, Andrawes FF, Barvenik FW, et al. Analysis of residual acrylamide in field crops. J Chromatogr Sci.1999;37: 240-44,.

2. Tareke E, Rydberg P, Karlsson P, et al. Analysis of acrylamide, a carcinogen formed in heated foodstuffs. J Agr Food Chem.2002;50:4998-5006.

3. JECFA, Joint FAO/WHO Expert Committee on Food Additives. Available from: http://www.who.int/ipcs/food/ jecfa/summaries/summary-report-64-final.pdf accessed 16 March 2005.

4. Amrein TM, Bachmann S, Noti A, et al. "Potential of acrylamide formation, sugars, and free asparagine in potatoes: A comparison of cultivars and farming systems", Journal of
Agricultural and Food Chemistry.2003;18: 5556-60.

5. Zhang Y. "Formation and reduction of acrylamide in mail lard reaction: A review based on the current state of knowledge", Critical Reviews in Food Science and Nutrition.2007;47:521-42.

6. Mottram D, Low M, Elmore J, et al. "The mail lard reaction and its role in the formation of acrylamide and other potentially hazardous compounds in foods", Acrylamide and Other Hazardous Compounds in Heat treated foods 2006: 3-22.

7. Maturi M, Alemzadeh I. Suppressed acrylamide formation during baking in yeast-leavened bread based on added asparaginase, baking time and baking temperature using response surface methodology. Applied Food Biotechnology. 2017.

8. Torang A, Alemzadeh I. Acrylamide Reduction in Potato Crisps using: Asparaginase from Candida utilis Commercial Asparaginase, Salt Immersion, and $\mathrm{pH}$ Treatment. International Journal of Engineering.2016;7:879-86.

\section{*Correspondence to:}

Alemzadeh I

Department of Chemical and Petroleum Engineering, Sharif University of Technology, Tehran, Iran

Tel: 982166165486

E-mail: alemzadeh@sharif.edu 